\title{
The characteristics and Revelations of Dutch Vocational Education System
}

\author{
Kai Zhu ${ }^{1,2}$ \\ ${ }^{1}$ Teaching Resources Center \\ Chongqing University of Education \\ Chongqing 400067, China \\ ${ }^{2}$ Chongqing City Jiulongpo District Wuzesheng Dahuan \\ Medical Skill \\ Research Institute \\ Chongqing 400050, China
}

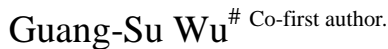 \\ Chongqing City Jiulongpo District Wuzesheng Dahuan \\ Medical Skill Research Institute \\ Chongqing 400050, China
}

\author{
Xin Zhao * Corresponding author \\ Department of Biological and Chemical Engineering \\ Chongqing University of Education \\ Chongqing 400067, China \\ E-mail: zhaoxin@cque.edu.cn
}

\begin{abstract}
This study was aim to given the characteristics and revelations of vocational education through the study on Holland vocational education system. Methods: This study has summarized the Holland vocational education system by the documents or other research reports. Then this study gives the suggestion of vocational education system establishing under these documents or other research reports. Results: The vocational education in the Netherlands develops very early, and it's considered as an equal with ordinary education, thus forming a perfect vocational education system. The vocational education system makes the unemployment rate in the Netherlands far lower than that in other European countries. Therefore, understanding the Dutch vocational education system is of great significance for the development direction of vocational education in our country and the reduction of unemployment. Conclusion: Our vocational education need the reform, the reform could combine our country's situation with experiences of the advanced country such as Holland.
\end{abstract}

Keywords—Netherland; Vocational education; revelation

\section{INTRODUCTION}

The Netherlands is one of the developed European countries, and its vocational education has its own characteristics, especially secondary vocational education which attaches great attention from the government. Vocational and Adult Education Act separates vocational education from ordinary education for the first time to strengthen the planning of vocational education resources as a whole, forming a perfect vocational education system. From 2009 to 2012, the unemployment rate in the Netherlands are $4.1 \%, 4.7 \%, 5.4 \%$ and $4.1 \%$ respectively, which is far lower than that of the average unemployment rate of European countries as $12.8 \%, 14.2 \%, 14.7 \%$ and $16.7 \%$ [1]. Therefore, to learn from professional education in the Netherlands, especially its hierarchical system, is necessary for the development of vocational education in our country and improves our employment rate.

\section{THE CHARACTERISTICS OF VOCATIONAL EDUCATION IN THE NETHERLANDS}

The Dutch government promulgated Vocational and Adult Education Act in 1996, which includes all kinds of vocational and adult education and separates vocational education and ordinary education for the first time [2]. The main goals are to strengthen the planning of vocational education resources as a whole, improve the quality of vocational education, strengthen connection between vocational education and market, coordinate vocational qualification certificate system and reduce the dropout rate of vocational school. Subsequently, according to the act, the Dutch Ministry of Education, Culture and Science merged vocational schools from 500 to 63 , which greatly enhanced managerial ability and education level of vocational schools and obviously improved its comprehensive ability [3]. In the reform process of vocational education system in the Netherlands, Dutch Vocational Education and Training Committee and Dutch Industry and Vocational Education Association played a very important synergistic role. Dutch Vocational Education and Training Committee is a vocational school organization, joined by voluntary application. Its main functions are to promote the importance of vocational education in economic construction and social development, coordinate the relationship between vocational school and industries and improve the conditions and image propaganda of vocational schools. Dutch Industry and Vocational Education Association is an organization for industries and vocational education, whose aims are too closely connect industries and vocational education to constantly improve the education level, put forward vocational qualification standards, provide employment information, ensure internship of vocational school students and set up a test center to be responsible for the vocational qualification 
certificate examination [4]. $30 \%$ of higher vocational education schools are public in the Netherlands, while $70 \%$ are private. As early as in 1917, the Dutch government published a policy on full subsidy for the cost of private schools, thus establishing financially equal status of private schools to public schools. Building schools is controlled by the government, and the schools pay attention to establish highquality majors, so there is no survival problems brought by inter collegiate competitions. As a result, a comprehensive vocational school is built in an area and it sets up different branches, which own different majors, forming standardized and collectivized franchising development model in an area [5].

Dutch vocational education training system is mainly divided into three stages, namely pre-vocational secondary education (VMBO), secondary vocational education and training (MBO) and higher vocational education (HBO) [6]

As for pre-vocational secondary education stage, the length of schooling is 4 years. The first two years study basic theory courses, which is the same as courses of pre-college education and ordinary high school. In this way, it can provide an opportunity for students who have chosen pre-college education or ordinary high school to choose a college preparatory education or ordinary high school education to shift to vocational education schools. The last two years learn and train related specialized courses, which prepare for further vocational education. During the period of learning, students have four ways, including theoretical study, combination theory and practice, career-oriented study to prepare for longterm secondary vocational school and career-oriented study to prepare for short-term secondary vocational school. Each approach can provide four fields of study, including technology, social assistance and welfare, economic and trade and agriculture. After graduation, students can enter higher secondary vocational education school or take part in all kinds of short-term training courses.

As for secondary vocational education and training stage, it can be divided into five levels, including associate, basic professional level, professional level, middle management level and expert. From associate level to expert level, it needs only half a year and longest for 4 years. Besides, expert level study must complete the middle management level at first, and spend 1 or 2 years in the actual work post, which avoids "experts" without practical experience. During this study time, there are two kinds of learning ways. One is full-time, which means students spend $40 \%$ to $80 \%$ of the time at school and $20 \%$ to $60 \%$ of the time in company. Training time accounts for $20 \%$ to $60 \%$ of the total hours. The other is apprenticeship in which students are both employees and students. They spend 1 or 2 days a week at school and 3 or 4 days in the company. Training time accounts for $60 \%$ to $80 \%$ of the total hours and training posts are provided by the enterprise [7]

As for higher vocational education stage, it is mainly carried out by higher vocational colleges, and the length of schooling is four years. Higher vocational colleges can not only provide students with a full-time study, but also part-time courses. In the four years, students mainly study basic theory courses in the first year and enter the second year of study if they can pass the examinations. Students will freely choose different majors in the second year. In the third year, students can get an internship in the enter prises. If they are willing to work in the enterprise, they can continue to complete their studies in an amateur way. In the fourth year, they are required to finish the graduation design. The Dutch government thinks highly of the higher secondary vocational education stage. Higher vocational colleges account for about $80 \%$ of all kinds of colleges and universities set up throughout the country. Meanwhile, more than $50 \%$ of the people who are educated receive vocational education in the Netherlands, while only about $6 \%$ enter research universities. In terms of employment, students who receive secondary or higher vocational education can find a job more easily [8]. The Dutch government sets up 56 kinds of professional qualification certificate for vocational education. Vocational qualification standards are set by the industry associations and approved by Dutch Ministry of Education, Culture and Science, and vocational qualification certificates are conferred by the vocational schools. If students who receive vocational education want to find a job, they only need vocational qualification certificate of basic level. However, If they want to further their education in colleges and universities, they must get vocational qualification certificate of middle management level during secondary vocational education (MBO). If the on-the-job students get expert certificate, they can also get a degree which is equal to a bachelor's degree and obtain corresponding international vocational qualification certification with strong specialty [9].

\section{REVELATIONS TO VOCATIONAL EDUCATION IN OUR COUNTRY}

It is necessary to make vocational education reform goals clear. After entering into the 21 st century, the process of industrialization in our country speeds up and demand for high-qualified talents with professional skills increase greatly, so this is a good opportunity for the development of vocational education. In terms of the development of secondary vocational education, it is important to strengthen macrocontrol, increase funding and propaganda for vocational education, and change people's bias to vocational education. Besides, it is also necessary to closely combine market demand with labor employment, develop cooperation between universities and enterprises and between work and study, forming a flexible, open, independent and modern vocational education system with Chinese characteristics, reasonable structure and various forms, which can obviously improve qualities of students in vocational colleges and speed up the training of skilled talents needed by production, construction, management and service line. To adhere to employment as the guidance needs changing the traditional vocational talent training mode, which is limited in laboratories and disjoints with enterprises. Vocational education doesn't put an end to one's education, as no one can get all the knowledge and skills that they need in the future career by one-time. Therefore, we should make vocational education adhere to the basic principle that is, service for the purpose and employment as the guidance and actively promote vocational education to shift from the planned training to market-drived model, from examination-oriented to employment-oriented. To promote the close combination between vocational education and production, technology promotion and social services, the vocational schools should actively carry out order training 
model to strengthen vocational guidance and entrepreneurship education, set up perfect vocational college graduates employment and business startups service system, and promote better vocational education towards society and market. Vocational education should cultivate students who can master knowledge in certain professional field and make them possess the ability of autonomous learning, not only teach them the fish but also how to fish, which is beneficial for their long-term and personal interests. There are many different kinds of problems existing if we want to strengthen the construction of exemplary vocational colleges and secondary vocational education in our country, including meticulous classification, multi-headed administrative management and barriers between different departments. Meanwhile, low-leveled and repeated setting of schools and majors is serious, while structured education resources waste is very outstanding. On the basis of integration of resources, deepened reform and innovated mechanism, we should lay emphasis on the construction of high-leveled demonstrative secondary vocational schools and higher vocational colleges which cultivate high-qualified skilled students. Besides, the government should increase investment in vocational education, and make every school own simulated practice places according to their majors except for the due teaching facilities. Students are exposed to the enterprise environment since their entrance to schools in those places run according to the requirement of actual industrial production. It is important to enhance vocational schools' ability of cultivating highqualified skilled talents and prompt them to play an exemplary role in deepening reform and innovating system and mechanism. Employment admittance system should be strictly implemented, and to improve vocational qualification certificate system should promote and standardize vocational qualification certification system and strengthen the management of professional skill appraisal, evaluation of professional personnel qualification and issue of professional qualification certificate. Double certificates system in which students can get a degree certificate and a professional vocational qualification certificate when graduation at the same time should be gradually carried out to establish a vocational qualification standard system which can reflect the development of economy and labor market.

\section{ACKNOWLEDGMENT}

The present study was supported by Special Transformation Research of Teaching Reform Research Project of Chongqing University of Education (ZXJG03).

\section{REFERENCES}

[1] Unemployment rates of the population aged 25-64 by level of education [EB/OL]. (2014-12-11) http://ec.europa.eu /eurostat/web/lfs/data/maintables.

[2] J. Sung, "Vocational education and training andemployer engagement: an industry-led sectoral system in the Netherlands," Int. J. Train. Dev., vol. 14, pp. 16-31, January 2010.

[3] X.L. Meng, "Education system and characteristics of Holland," World Educ. Inform., vol. 2006, pp. 33-34, February 2006. (In Chinese)

[4] J.P. Wang, "The chaaracteristics of vocational and technical education in Belgium and Holland and implications," Vocat. Tech. Educ. (Educ. Sci.) vol. 31, pp. 62-64, August 2002. (In Chinese)

[5] J. Dronkers, "The percarious balance between general and vocational education in the Netherlands," Eur. J. Educ., vol. 28, pp. 197-207, September 1993.

[6] M. Mulder, T. Weigel and K. Collins, "The concept of competence concept in the development of vocational education and training in selected EU member states - a critical analysis," J. Vocat. Educ. Train., vol. 59, pp. 65-85, March 2006.

[7] Education section of embassy of the People's Republic of China in the Kingdom of the Netherlands, "Holland Vocational Education Overview," World Educ. J., vol. 2012, pp. 44-46, August 2012. (In Chinese)

[8] Z.D. Xu, "Holland pavilion-Holland education system and its reform," Shanghai Educ., vol. 2010, pp. 45-47, March 2010. (In Chinese)

[9] Y. Liu and Y. Yan, "Discussion on vocational and technical education and training in Holland,” Educ. Vocat., vol. 2006, pp. 43-44, June 2006. (In Chinese) 